\title{
К ВОПРОСУ О РОЛИ СОВРЕМЕННЫХ ТЕХНОЛОГИЙ ОБУЧЕНИЯ В ОБРАЗОВАТЕЛЬНОМ ПРОЦЕССЕ
}

\section{TO THE QUESTION ABOUT THE ROLE OF MODERN LEARNING TECHNOLOGIES IN THE EDUCATIONAL PROCESS}

\section{G. Kuznetsov}

Summary: The article provides an overview of some pedagogical technologies from the perspective of the humanistic paradigm, their role in the formation of personality. The educational and psychoemotional significance of these technologies is considered. The author analyzes the role of teachers and the need to train a new generation of teachers who possess both modern technical means and knowledge of modern world science.

Keywords: pedagogy, personality, technology, teacher, empathy, training, method, development, children, love, future, noosphere.

\author{
Кузнецов Геннадий Тарасович \\ к.б.н., дочент, ГБОУ ВО «Ставропольский \\ государственный педагогический институт», \\ Ставрополь \\ natali.kuznetsova.48@mail.ru
}

Аннотация: В статье представлен обзор некоторых педагогических технологий с позиции гуманистической парадигмы, их роли в формировании личности. Рассматриваются их обучающее и психоэмоциональное значение. Анализируется роль учителя и необходимость подготовки педагогов нового поколения, владеющих как современными техническими средствами, так и знаниями современной мировой науки.

Ключевые слова: педагогика, личность, технология, педагог, эмпатия, обучение, метод, развитие, дети, любовь, будущее, ноосфера.

Учебные заведения наиболее чувствительны к изменениям, происходящим в обществе. Настоящее время характеризуется активными преобразовательными процессами. Традиционные методы обучения и воспитания исполнителей не соответствуют запросу времени. Необходимы активные методы, направленные на активизацию личностного развития ребенка. И это не только подготовка к ЕГЭ. Следует думать о технологиях воспитания и обучения в рамках формирования личности.

Характеризуя практику современных технологий, голландский психолог Карл Ван Парререн, выделяет несколько принципов, которые должны лежать в основе современных педагогических технологий. [10, с.5-7]

1. Формирование устойчивой мотивации к учебной деятельности; это может основываться на личном опыте учащихся.

2. Учить в сотрудничестве, в диалоге.

3. Вести постоянную диагностику результатов обучения, с корректировкой по мере необходимости.

4. Дифференцировать учебные единицы и задачи в зависимости от категории учащихся и их уровня подготовки и мотивации.

5. Обеспечить эффективность интериоризации необходимой для конкретного случая обучающей моделью: предметно ориентированной, личностно-ориентированной на разнородных уровнях (материальный, перцептивный, умственный)

6. Использовать соответствующий темп и средства (устная речь, письменная речь, искусственный язык, а также графические модели и символы). 
7. Обучать и помогать учащимся на уровне их фактических способностей. Избегать формального и механического запоминания. Мотивировать на осознанность.

8. Использовать принятую систему самооценивания (подобно системе Ш.А. Амонашвили). Приучать к самоанализу своих результатов.

9. Иметь набор заданий, творческих, нетиповых, цель которых исключить закрепление ригидности действий, речи, мысли.

10. Поощрять инициативу и творчество. Обеспечивать условия для создания климата в классе, ведущего к формированию социально интегрированной личности учащегося.

Материалы ЕГЭ и его результаты ясно дают понять, что успешные выпускники - это подростки с достаточно высоким интеллектом и хорошей подготовкой. Интеллект во многом определяется генетическими факторами, но для его проявления требуется развитие, а для успешной сдачи экзамена необходима серьезная работа с материалом.

Этим требованиям во многом должен соответствовать современный педагог. Ему необходимо уметь ориентироваться в многообразии интегративных подходов к развитию детей, в широком спектре современных технологий.

Рассмотрим содержание некоторых педагогических технологий с точки зрения их вклада в развитие креативной современной личности.

\section{Развиваюшее обучение. Технология проблемного обучения.}

Развивающее обучение направлено на развитие всей целостной совокупности качеств личности.

Считается, что эта технология базируется на психолого-педагогических представлениях американского ученого Д. Дьюи. [2, с.325-328] Следует отметить, что идеи проблемного обучения звучат и в работах И. Г. Песталоцци [[2, с140-145], и К. Д. Ушинского [2, с. 286,-288], и Л. С. Выгодского [5, с. 513-514], предложившего периодизацию детского развития, в которой выделил критические и литические периоды. Именно он ввел положение о зоне ближайшего развития, располагающегося между уровнем актуального и потенциального развития психики. Исходя из этих представлений Л.С. Выгодский утверждал, что содержание обучения должно быть по уровню выше актуального развития, чтобы обеспечить само это развитие, но не выходить за пределы зоны ближайшего развития, так как в этом случае учебный материал просто не будет усвоен. Проблемные технологии здесь выступают в качестве развивающей среды.
Идеи Л.С. Выготского получили свое развитие в работах А.Н. Леонтьева, в рамках его психологической теории деятельности [4, с.126] Дальнейшее развитие теория развивающего обучения получила в экспериментальных работах Л.В. Занкова, Д.Б. Эльконина, В.В. Давыдова и др. [2, с.394-397]. В их концепциях обучение и развитие предстают как система диалектически взаимосвязанных сторон одного процесса. Обучение признается движущей силой психического развития ребенка, становления у него всей совокупности качеств личности. Концепция развивающего развития в настоящее время реализуется через конкретные обучающие технологии, в том числе и через проблемное обучение.

Этот вид обучения основывается на создании особого вида мотивации, а именно поставленной проблемы. Ее реализация лежит через цепь проблемных ситуаций, которые могут быть самыми различными, как по уровню сложности, требующих дополнительной информации, так и по логике взаимосвязанных между собой компонентов, хотя и не требующих дополнительных знаний. Проблемная ситуация несет в себе эмоциональный заряд азарта, что само по себе является стимулом к поиску решения.

В современной теории проблемного обучения различают два вида проблемных ситуаций: психологическую и педагогическую. Первая касается деятельности учеников, вторая представляет организацию учебного процесса.

Педагогическая проблемная ситуация создается с помощью активизирующих действий, вопросов педагога, подчеркивающих новизну, важность, красоту и другие отличительные качества объекта познания. Проблемные ситуации могут создаваться на всех этапах процесса обучения: при объяснении, закреплении, контроле. Использование проблемных ситуаций способствует развитию самостоятельности мышления, углублению знаний, умению аргументировать свою позицию, развитие познавательных и творческих способностей.

\section{Игровые педагогические технологии.}

Эти технологии как никакие другие могут быть использованы и используются в качестве способов, развивающих психику.

Их особенностью является:

- четко поставленная цель

- предполагаемый результат

- познавательная направленность

Эта форма имеет игровую мотивацию, которая выступает как средство стимулирования детей к учебной деятельности. 
В педагогической литературе предлагается несколько классификаций групп игр в зависимости от поставленных воспитательных и обучающих целей. Как-то:

обучающие, тренировочные, контролирующие и обобщающие;

- познавательные, воспитательные, развивающие;

- репродуктивные, продуктивные, творческие;

- коммуникативные, диагностические, психотехнические и др.

Игры являются естественной потребностью всех млекопитающих. У человека игровая деятельность достигает наивысшего развития. Через игру ребенок приобщается к миру вещей и отношений. Через игру он имеет возможность самоутверждения и самовыражения, игра дает возможность самореализации и учит саморегуляции. Игра именно тот способ воспитания, который и может в полной мере воплотить идею опережающего развития. Вспомним замечательное высказывание Л.С. Выгодского о том, что педагогика должна ориентироваться не на вчерашний, а на завтрашний день детского развития.

Играют взрослые, реализуя свои интеллектуальные и физические возможности. Игра зачастую способствует новым научным идеям, помогает решить организационные и психологические проблемы в коллективе.

\section{Технология развиваюших игр} Б. П. Никитина. [7, 1-33]

Б.П. Никитин, сторонник представлений опережающего развития [6, с.1-60], физик по образованию, отец семерых детей. Свой опыт работы с детьми в рамках развивающего обучения он изложил в своих книгах. Большую роль он отводил играм с предметами: кубиками, рамками, картами, таблицами, конструкторами, мячами, палочками и т. п. По его мнению, развивающие предметные игры способствуют формированию технического творчества и развивают интеллект. В подобных занятиях могут быть использованы различные задачи в виде конкретных деталей конструктора или рисунка и даже целого сооружения. Задачи формируются в зависимости от возраста учеников и уровня их общей подготовки. Б.П. Никитин называл эти задания «задания-ступеньки», то есть подразумевалось постепенное усложнение задач, мотивировало учащихся к достижению более высокого уровня. Особенностью развивающих предметных игр является атмосфера свободного творчества, отсутствие какого-либо принуждения.

Анализируя применение игры в обучении и воспитании, можно выделить некоторые ключевые моменты, важные для формирования креативной социальной личности нового времени:
1. Отсутствие шаблона действий, хотя и имеются правила игры.

2. Необходимость быстрой ориентировки в изменяющейся обстановке игры.

3. Игра способствует развитию психических свойств личности: памяти, внимания, воображения, сообразительности, речи

4. Игра способствует развитию скорости как психических реакций, так и физической сноровки при выполнении практических заданий.

5. В игре формируются навыки коллективной деятельности.

6. С помощью игры происходит приобщение детей к пониманию необходимости правил и законов для нормальной жизни коллектива.

7. Благодаря игре формируется понимание необходимости выполнения этих правил и законов во имя сохранения самого общества как среды обитания личности. (это очень актуально для нашей страны)

8. Развиваются творческие способности.

\section{Информашионные технологии.}

В современной педагогической деятельности большое место занимают информационные технологии, то есть, те, что используют компьютерную, аудио и видео технику - технические информационные средства. Ускоряющаяся глобализация способствует росту коммуникативных сетей, и непосредственного включения в них России. Это ставит перед необходимостью активного развития всех телекоммуникаций, подготовки специалистов в этих областях, а также обучение пользователей всех уровней. Естественно, что образование ориентировано на подготовку поколения для вхождения в общемировое информационное пространство. Так среди информационных технологий выделяют технологии ИКТ (компьютерные) и дистанционного обучения.

В настоящее время компьютерные технологии стали неотъемлемой частью всего педагогического процесса. Компьютерные) технологии обучения направлены на оформление информации соответствующим образом для передачи ее посредством компьютера. В период карантинных мероприятий и удаленным обучением, связанным с пандемией covid-19, учебные заведения всех уровней активно использовали технологии дистанционного обучения, как в процессе изучения нового материала, так и во всех формах контроля.

Помимо широко известных, во многих отношениях прогрессивных технологий обучения, современная система образования позволяет использование альтернативных технологий, инновационных, по сути, зачастую отрицающих многие традиционные подходы. Среди них, авторские технологии. Здесь уместно вспомнить мето- 
дики обучения В.Ф. Шаталова, Ш.А. Амонашвили, С.Н. Лысенковой и многих других замечательных педагогов современности [8, с.9, с.57, с.141]. Особенность авторских методик заключается в их неповторимости другими участниками процесса. Используются элементы, часто дающие замечательные результаты, но целиком технологии остаются невоспроизводимыми. Это лишний раз доказывает известный тезис о том, что педагогика, являясь наукой, являет собой искусство. Неповторим опыт А.С. Макаренко, Я. Корчака, М. Монтессори, как и неповторимы жизненные обстоятельства, в которых они создавали свои педагогические системы. Тем не менее, их опыт требует своего изучения и применения по мере соответствия конкретным педагогическим обстоятельствам и данному времени.

\section{Мария Монтессори. Технологии саморазвития.}

\section{«Помоги мне это сделать самому» - девиз педаго- гики М. Монтессори.}

Эта технология была создана как альтернатива муштре и догматизму в обучении, распространенным в конце XIX века. [2, с.338-340].

М. Монтессори воспринимала ребенка как существо, способное к самостоятельному развитию, и определила главной задачей школы - поставлять «пищу» для естественного процесса саморазвития, создавать окружающую среду, которая способствовала бы ему.

Метод М. Монтессори состоит из трех основных частей: ребенка, окружающей (подготовленной) среды, учителя. Подготовка среды и подготовка учителя есть практический фундамент нашего воспитания. [2, с.338342].

Своей задачей М. Монтессори ставила всестороннее развитие ребенка, воспитание в нем самостоятельности. Ее подход характеризуется антропоцентризмом. И это при том, что у нее часто были особенные дети с большими проблемами в своем начальном развитии или в состоянии здоровья. Тем не менее, работая с детьми, педагог использует игровые и творческие методы, стремясь соединить в сознании ребенка мир предметный и мыслительную деятельность через индивидуальные и групповые формы занятий.

Огромная роль придается подготовленному учебному пространству. Здесь подразумевается, как психологически комфортная среда, так и физические удобства, такие как мебель, доступность пособий в соответствии с ростом детей и т. п. Все должно располагать к тому, чтобы ребенок стремился сам себя развивать. Помощь педагога заключается в возможности организовать выполнение задачи самостоятельно. Вместо натаскивания создание среды для саморазвития. Необходимая составляющая - чистота и порядок, необходимость их постоянного поддержания. Большое значение имеет эстетическое оформление помещения, красота. Но красота здесь не в украшениях и роскоши, а в гармонии линий и цветов, в простоте.

Метод Монтессори активно внедряется в жизнь с 1909 г. Открываются курсы по Монтессори-педагогике. К Марии приезжают педагоги из Лондона, Барселоны, Парижа. В те годы встретилась с Марией Монтессори и наша соотечественница Юлия Фаусек, которая первая в России открыла монтессорианский детский сад. [2, с.338342].

\section{Личностно-ориентированные технологии обучения.}

Так, современные школы Англии более ориентированы на личность школьника. Рыночная система существования общества более ориентирована на индивидуальную деятельность. Соответствующим образом организовано и бучение в школах. Более способные к наукам дети, быстро воспринимающие учебный материал, обучаются в классах, где углубленно изучают школьную программу. Подобные же группы имеются для школьников со средними и слабыми способностями. В этих школах отсутствует оценочная система действий ученика, часто унижающая его человеческое достоинство. В таких школах возможность определить свои возможности значительно шире. Одни приобретают высокий уровень знаний, другие находят себя в спорте, музыке или в другом виде творчества или практической деятельности. То есть, здесь мы видим направленность вектора педагогической деятельности не мешать ребенка быть самим собой и по возможности стать счастливым. В условиях авторитарной системы образования с комплексом обязательных к неукоснительному выполнению всеми заданных установок воспитать счастливого человека нереально. При личностно-ориентированном подходе слабая успеваемость не становится причиной изгнания человека на обочину жизни. Фундаментом всего учебно-воспитательного процесса во многих школах этого направления поставлено духовное воспитание и социальное развитие, что и создает психологическую базу для формирования в личности чувства собственного достоинства.

Гуманитарно-личностная технология «Школа жизни» (Ш.А. Амонашвили), представляет собой разновидность личностно-ориентированной технологии.[8, с.9-56].

В 1988-89 году Шалва Александрович работал вместе с А.А. Леонтьевым в уникальном коллективе - ВНИК «Школа» [1, с. 1-340]. Это было содружество ученых, перед которыми была поставлена задача: создать науч- 
но-методологические основы образовательной системы нового поколения. Это был период бурного всплеска педагогических идей. Правда, быстро был завершен. Началось засилье информационно-технических технологий.

Один из ведущих принципов гуманитарной педагогики Шалвы Александровича Амонашвили заключался в том, чтобы никогда не сравнивать успехи детей. Допускалось лишь сравнение с результатами собственной работы. Отвергались состязательность и соперничество, на первом плане были поставлены взаимопомощь и взаимовыручка. Он учил детей радоваться успехам друг друга. Большая роль отводилась психоэмоциональному фактору. Это принципы исключительно духовного воспитания, полностью опровергающие подходы авторитарной педагогической парадигмы. Его ученики - его соратники, участвующие в продумывании построения уроков, заданий, даже учебников. Его педагогика есть олицетворение в полном смысле науки о Любви к детям. Кода он начинал свою педагогическую деятельность, он получил для руководства школу, в которую отправляли недоразвитых, отсталых детей. Проведенная через несколько лет министерская проверка не обнаружила таких детей. Ответ директора был прост: «Детей надо любить и с ними заниматься» [8, с.9-56].

«За 60 лет педагогической деятельности он создал три взаимосвязанных системы:

1. Учение гуманно-личностной педагогики. Сформирована к началу 90-х годов XX века. Может быть реализована в настоящее время.

2. Школа Жизни. Разработана во второй половине 90-х годов XX века. Ее можно будет осуществить во второй четверти XXI.

3. Педагогика Любви и Света. Сотворена в первое десятилетие XXI века. Для Вечности. Может быть востребована и реализована во второй половине XXI века. Местом конденсации идей этой педагогики выступает Ноосфера, или как ее определяет сам Шалва Александрович-находящаяся вокруг Земли Сфера Сердца.»

\section{Предметно-ориентированные технологии.}

Они занимают большое место среди современных обучающих систем.

Это технологии, так называемой «знаньевой» педагогики, во многом альтернативной личностно-ориентированная педагогике. Методы такой технологии направлены на повышение уровня знаний по конкретным предметам. В рамках этой технологии мы можем говорить о технологии концентрированного обучения, обучения в вузе или в школе. Технологии предусматривают как содержание образования с возможным его изменением, так и развитие личности учащегося. Большая роль в применении предметно-ориентированной технологии принадлежит специфике предмета и возрастным особенностям учащихся.

1. Подводя итоги рассмотренным системам обучения и воспитания, отметим, что общество вступило в техногенную эпоху своего развития. Новое время рождает новые требования к личности. Требуются новые знания, новые умения и навыки и, следовательно, новые подходы к их приобретению. Перед образованием стоят грандиозные задачи. Для их решения нужны специалисты нового поколения, владеющие как современными техническими средствами, так и знаниями современной мировой науки. Но педагог - это не ученый, находящийся в поиске нового знания. Это носитель знания для нового поколения. Какими бы техническими средствами не владело бы общество, оно состоит из людей, и психическую компоненту у него никак невозможно отменить. Поэтому говоря о подготовке педагогов нового поколения, необходимо иметь ввиду его психолого-педагогическую грамотность, помимо великолепного знания своего предмета. Но и этого недостаточно. Педагог имеет дело с детьми, еще формирующимися душами и требует душевного отношения. Все великие педагоги всех времен, достигшие успехов в своем титаническом труде, говорят о необходимости Любви к питомцам, к предмету, избранному для обучения. В своей работе «Педагогика индивидуального действия» А. С. Макаренко пишет о важности выбора воспитателя. Он должен быть коммуникабельным, уметь разговаривать с ребенком, быть организатором, иметь чувство юмора, владеть голосом, позой. Педагог должен обладать качествами коллективной личности. А.С. Макаренко считает, что всему этому можно и необходимо учить [3, с. 417-420].

«Сердце отдаю детям», книга, написанная Василием Александровичем Сухомлинским, и это лейтмотив всей его педагогической деятельности, которой он посвятил всю свою жизнь. С 1944 года и до конца своих дней (1970) он оставался директором средней Павлышской школы. Эта школа, с ее принципами и требованиями, явилась плодом педагогического творчества ее директора и коллектива единомышленников педагогов. За годы работы и осмысления происходящего как в школе, так и в обществе в целом, В.А. Сухомлинский сумел создать свою оригинальную педагогическую систему. Эта система основывается на принципах гуманизма, где личность ребенка признается высшей ценностью. В основе работы лежат принципы, учитывающие возрастные и индивидуальные особенности воспитанников. Большая роль принадлежит эмоциональности всех проводимых мероприятий, так как это свойство детей, обусловленное преобладанием у них подкорковых процессов. Формирование коры происходит медленнее и позже [9, с. 151-170]. 
В.А. Сухомлинский, как все выдающиеся педагоги, четко осознавал великую ответственность своей деятельности перед будущим. Педагогика-наука футуристическая. Она во многом создает, лепит это Будущее. В переводе с латыни школа-это лестница, отражающая духовное восхождение человека. Но школу творит Учи- тель. В переводе с санскрита - это «носитель света».

Будущее общества тесно связано с тем, каков будет Учитель, и его подготовке должно быть уделено особое внимание. Критерием при отборе абитуриентов должно быть качество высокой пробы.

\section{ЛИТЕРАТУРА}

1. Амонашвили Ш.А. Основы гуманной педагогики в 20 кн. М.: «Свет» 2017, т.1, 304c.

2. История педагогики. Под ред. 3 И. Васильевой. М.: изд. Центр «Академия», 2009, 428 с.

3. Макаренко А.С. Методика организации воспитательного процесса. Педагогические сочинения в 8т.-М. 1983 - т.1 с. 417-420

4. Маклаков А.Г. Общая психология. СПб - Питер, 2001,592с.

5. Марцинковская Т.Д. История психологии. М.: изд. Центр «Академия», 2009, 544 с.

6. Никитин Б.П., Никитина Л.А. Мы, наши дети и внуки. в 2 томах. — М: «Самокат», 2015.60 с.

7. Никитин Б.П. Развивающие игры. М.: «Педагогика», 2015, 33 с.

8. Педагогический поиск. Сост. И.Н. Баженова. -М.: «Педагогика», 1987, 544 с.

9. Сухомлинский В.А. Павлышская средняя школа. М.: «Педагогика, Педагогика»,1987, 383 с.

10. Чупрасова В.И. Современные технологии в образовании. Курс лекций. Владивосток.: Дальневосточный государственный университет, 2000, 51 с.

\section{○ Кузнецов Геннадий Тарасович (natali.kuznetsova.48@mail.ru).}

Журнал «Современная наука: актуальные проблемы теории и практики»

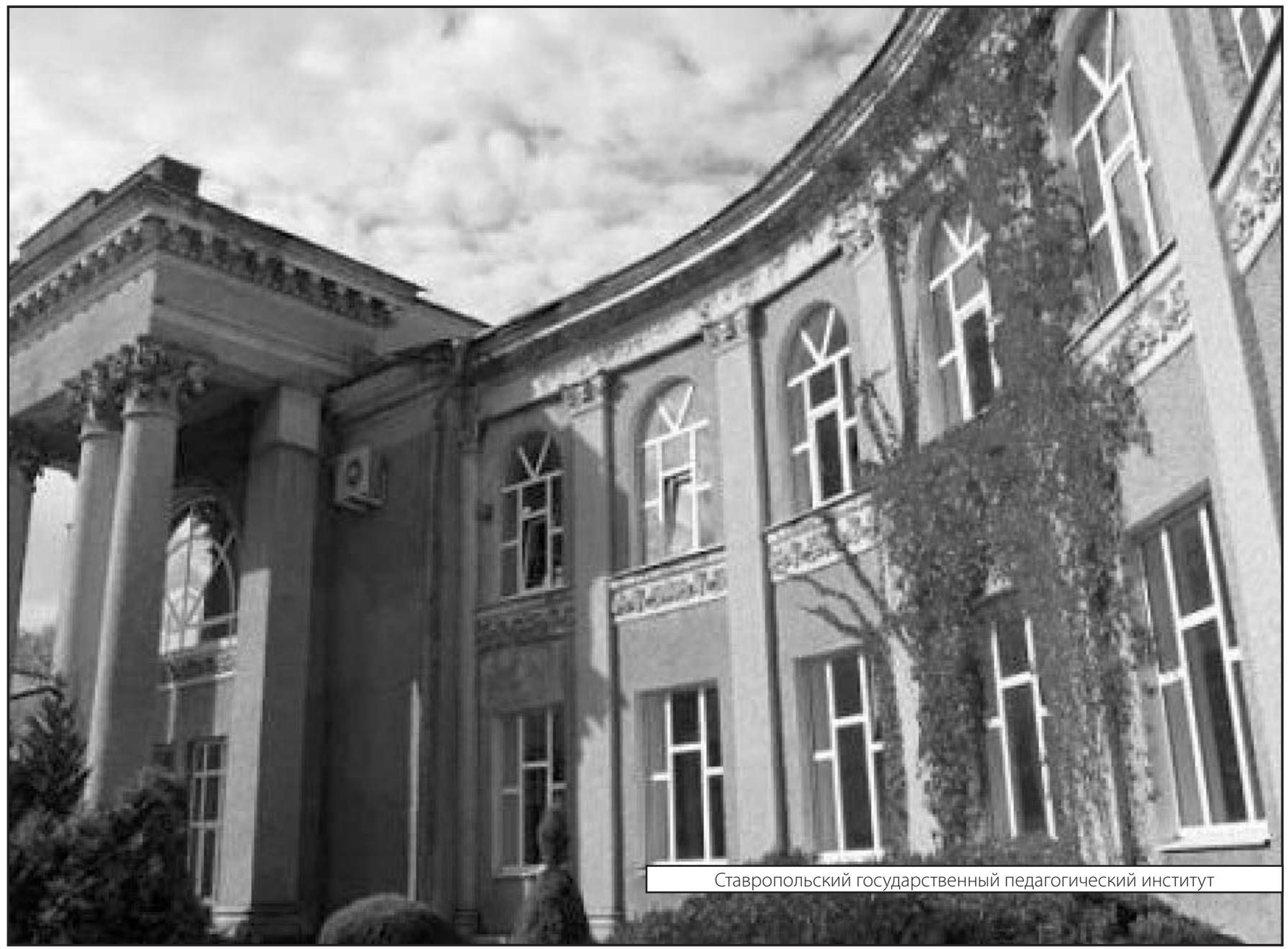

